\title{
Global justice and health systems research in low and middle-income countries
}

\section{Introduction}

More than a decade ago, Benatar and Singer argued that "a new, proactive research ethics . .. must ultimately be concerned with reducing inequities in global health and achieving justice in health research and health care." ${ }^{1}$ Towards this objective, a limited amount of recent scholarship has started to consider whether a theoretical basis exists for the position that international research should help promote global health equity and, if so, what the implications are for its conduct. ${ }^{2}$ Theories of justice from political philosophy establish obligations for parties in high-income countries to improve the health of parties in low and middle-income countries (LMICs). ${ }^{3}$ These theories have been shown to provide grounds for the claim that international research should be conducted to advance justice in global health. ${ }^{4}$ What this means for research actors from high-income countries is the focus of a recently proposed ethical framework: 'research for health justice'. ${ }^{5}$

'Research for health justice' requirements are derived from the health capability paradigm, a theory of justice that extends the work of Sen and Nussbaum and specifically addresses health. The health capability paradigm establishes a universal obligation to efficiently reduce shortfall inequalities in individuals' health capabilities. ${ }^{6}$ Health capabilities refer to individual ability and freedom to achieve certain health functionings (i.e. avoiding preventable morbidity and mortality). To ensure individuals' health capabilities, certain entitlements must be provided, including public health and health care interventions and services as well as the institutional structures and norms that facilitate access to them. ${ }^{7}$ Equality in health capabilities is measured in terms of shortfall equality. As health capabilities are not directly observable, reducing shortfall inequalities in individuals' health capabilities refers to diminishing the gap in their health status from the optimal level (the highest level of health 
achieved worldwide in terms of morbidity and mortality indicators). Health functionings or achievements map directly on to health capabilities, so individuals' health status can be used as a proxy indicator of their health capability. ${ }^{8}$

States have the primary responsibility to foster their populations' health capabilities. Priority is given to addressing shortfalls in the health capabilities of those farthest from the optimal level of health. ${ }^{9}$ Achieving justice in health then means first meeting the health entitlements of people who are worst-off in health terms ${ }^{10}$ within states. Where states are unable to meet this responsibility, justice requires that global actors ${ }^{11}$ assist states to meet their obligation and build states' capacity to do so on their own. ${ }^{12}$ In doing so, global actors should give priority to worst off states-namely, LMICs. ${ }^{13}$ The aim here is for LMICs to become capable ensuring their populations' health capabilities in their own right rather than to be perpetual recipients of rich countries' help.

The 'research for health justice' framework's starting premise is that the goal of international research is to reduce shortfalls in the health capabilities of worst-off individuals in LMICs through both the conduct of collaborative research and efforts to build host country research capacity. ${ }^{14}$ The framework provides guidance on three aspects of international researchselection of research targets, research capacity strengthening, and post-study benefits-that can connect the enterprise with the broader justice agenda of the health capability paradigm. It assigns obligations to external research actors from high-income countries (e.g. governments, research funders, sponsors ${ }^{15}$, and researchers) in relation to these aspects. ${ }^{16}$ These actors are allocated specific obligations according to the paradigm's functional requirements principle. This principle gives parties obligations because the functions they typically assume make them particularly capable of fulfilling the obligations. ${ }^{17}$ Thus, external research actors from high-income countries have specific obligations that are consistent with their roles in the global health architecture. 
Given its starting premise, the 'research for health justice' framework takes the position that health systems research should be a major focus of international research investment. ${ }^{18}$ Although it is necessary for new disease-specific interventions to be developed and existing disease-specific interventions to be adapted for resource-poor settings, making this the primary aim of international research will have a limited impact upon the health capabilities of the worst-off within LMICs. Enabling health systems are required to ensure individuals' health capabilities. ${ }^{19}$ Yet significant knowledge deficits exist regarding what health system barriers are hindering the delivery and affordability of health care and services in LMICs, particularly to vulnerable and disadvantaged sub-populations, and what strategies are required for overcoming them. ${ }^{20}$ It is unclear how the governance, service delivery, financing, and human resource components of health systems in LMICs can best be organised to reduce shortfall inequalities in individuals' health capabilities. This means that the full benefits of new and existing interventions and services cannot be realised without health systems research (HSR). ${ }^{21}$ Such research has been repeatedly identified as an indispensable means to the goal of achieving health equity. ${ }^{22}$ The 'research for health justice' framework, therefore, considers HSR to be a high priority.

Despite this, 'research for health justice' requirements have only been developed for international clinical research. ${ }^{23}$ Similarly, other bioethics scholarship on international research and global justice has primarily focused on clinical research. ${ }^{24}$ Critical examination of what is owed in HSR in LMICs has not yet been done. This is problematic because externally-funded HSR is increasingly being performed in LMICs and has distinctive features relative to clinical research that restrict the applicability of existing ethical guidance. ${ }^{25}$ Alternative or nuanced guidance is likely needed to link HSR to the reduction of health disparities between and within countries.

HSR has been defined as the production of new knowledge to improve the performance of health systems. ${ }^{26}$ It investigates how and why health systems do not meet their goals and 
develops means (i.e. systems level interventions) to improve health systems' functioning so that they do. ${ }^{27}$ Here, the term health system is used to refer to both public health and health care systems. ${ }^{28}$ Systems level interventions might consist of a novel delivery mechanism for existing efficacious health services, a new method of creating demand for existing health services, an output-based payment mechanism to boost staff productivity at health facilities, or a community-based health insurance mechanism. These interventions tend to generate impacts across a range of diseases. Relative to clinical research, HSR's distinctive features include:

- a focus on health systems rather than specific diseases;

- a focus on populations rather than individuals;

- being explanatory, descriptive, or evaluative;

- being question-driven, context-driven, and policy-driven; and

- being more closely linked to the development field.

This paper takes a first step in developing ethical guidance for HSR from a global justice perspective. It expands the 'research for health justice' framework to externally-funded HSR in LMICs, describing how elements of the health capability paradigm are applied in light of HSR's distinctive features. These elements include the paradigm's requirements for health systems, the theory's main principles (i.e. justice should be assessed in terms of shortfall inequalities in health capabilities; functional requirements; priority to the worst-off; efficiency), and its guidance on how global justice is promoted (direct assistance, capacity-building, shared health governance). ${ }^{29}$ The resultant (expanded) framework offers guidance on how research targets should be selected (at the national and project levels), what research capacity strengthening should be performed, and what post-study benefits ought to be provided and to whom in order to link HSR in LMICs to increased freedom for the worst-off to achieve good health. It identifies the obligations of external research actors from high- 
income countries to put this model of HSR into practice, providing guidance on what equityoriented HSR demands in terms of funders' investments and researchers' conduct. ${ }^{30}$

\section{Selecting a research target}

Priority setting (national or sub-national level)

To ensure the health capabilities of their populations, states have an obligation to (amongst other things) develop and maintain public health, health care, and health research systems. These systems are ultimately responsible for ensuring the financing of, access to, and quality of evidence-based health-related goods and services. ${ }^{31}$ A key function of national health research systems is to regularly set priorities for research, including HSR, to guide (external and internal) funders and researchers. National and sub-national obligations exist to ensure that such priorities are set regularly. However, evidence indicates that many LMICs fall short of this obligation, particularly with respect to HSR. There is little demand or push for priority setting exercises to be undertaken for HSR within LMICs. The governments of such countries often do not have national processes in place to set health research let alone HSR priorities. ${ }^{32}$ In the 1990s, many LMICs did set health research priorities under the Essential National Health Research movement, but these efforts frequently failed to yield the identification of HSR priorities ${ }^{33}$ and were not undertaken more than once in many countries, though there are exceptions. ${ }^{34}$

Where states fall short of their obligations of justice, global actors acquire secondary obligations to assist them that are consistent with their functions. Accordingly, entities that have expertise in research priority setting like the Alliance for Health Policy and Systems Research, the Council on Health Research for Development (COHRED), and the World Health Organization (WHO) must help LMICs to set HSR priorities at the national and subnational levels (and build their capacity to do $\mathrm{so}^{35}$ ). The 'research for health justice' 
framework identifies a number of requirements for this process of equity-oriented, global actor-facilitated priority setting.

Typically, HSR issues have been incorporated into priority setting exercises either through the lens of a specific disease or as a category separate from specific diseases. ${ }^{36}$ Of the two options, only the latter would be permissible to rely upon to set HSR priorities under 'research for health justice'. To identify research priorities, disease-driven priority setting processes generally determine what burden of specific diseases may be averted by: developing new drugs and technologies, improving existing drugs and technologies, or extending the uptake of existing interventions. ${ }^{37} \mathrm{HSR}$ falls into the third of these categories and may be identified as a priority where a significant burden of a disease is due to poor intervention uptake. However, such priority setting processes do not serve HSR well. Ranson and Bennett note that

[m]any health systems research questions stand to provide benefits for multiple different diseases. Linking health systems research questions to specific diseases, rather than seeing them in total, results in these topics being systematically deprioritized. $^{38}$

This devaluing of HSR relative to disease-driven types of health research is inconsistent with 'research for health justice' because it will slow progress towards global health equity by endorsing inappropriately low levels of funding to be directed to HSR. As a result, the framework prohibits using disease-driven methods alone to set national health research priorities or to identify HSR priorities.

'Research for health justice' also does not support priority setting exercises where HSR priorities are set for specific diseases such as the Malaria Eradication Research Agenda's recent work to identify HSR priorities for malaria. ${ }^{39} \mathrm{HSR}$ generates evidence that applies to the health system as a whole and, therefore, frequently addresses multiple diseases at once. If HSR priorities are identified on a disease-by-disease basis, there will likely be 
considerable overlap amongst HSR priorities for different diseases. This, in turn, will promote funding being allocated to multiple, narrowly-focused projects of a similar purpose as opposed to fewer, systems-focused projects. Such an outcome is inconsistent with the health capability paradigm, which applies efficiency considerations to equity goals. States and global actors should fulfil their obligation to reduce shortfall inequalities in individuals' health capabilities using as few resources as possible. ${ }^{40}$

An alternative approach is to focus on HSR questions separately from disease-driven questions and to rely on a more interpretive exercise to set HSR priorities. While such an approach is more consistent with 'research for health justice', it must be carried out in a particular way to meet framework requirements. It also does not change the fact that a way of comparing the value of HSR and biomedical research priorities to one another must be developed if separate HSR and disease-driven research priority setting processes are used. If a means of comparison or integration is not developed, the inherent weakness in employing two separate processes is that doing so will give little indication of the importance of HSR priorities relative to disease-driven research priorities. ${ }^{41}$

Interpretive priority setting exercises generally involve a consultative process during which a range of stakeholders are convened (possibly at multiple stages) to identify priority research topics and/or questions (under those topics). Criteria for ranking research topics/questions are determined and used to generate a list of priorities that is then validated by all stakeholders. Where global actors assist LMICs to set national and sub-national HSR priorities via an interpretive approach, 'research for health justice' demands that the process primarily incorporate local stakeholders' perspectives. This is because health systems are complex social systems that vary widely based on the specific circumstances of individual countries. ${ }^{42}$ As a result, unlike clinical or biomedical research-[HSR questions] should be driven by understanding of local contexts. At all stages of the research endeavour...[HSR] will 
benefit from being embedded within a particular context and close engagement with local actors. ${ }^{43}$

National and sub-national stakeholders are in the best position to determine their country's priorities for HSR as opposed to external stakeholders. External research funders (donors) and other global actors should not strongly participate in the setting of national or subnational HSR priorities in LMICs. Global HSR priorities should also not be relied upon to determine national HSR priorities in LMICs, as they may not reflect each country's unique situation adequately. (It is acceptable for national and sub-national priorities to align with global priorities but only once they have been identified independently of global priorities.)

As the health capability paradigm endorses a specific system of governance, global actorfacilitated priority setting must be consistent with that system—namely, shared health governance. Two key features of shared health governance are shared sovereignty and reaching consensus on decisions. Shared sovereignty entails "inclusive decision making and shared authority". ${ }^{44}$ When applied to the context of HSR priority setting, this requires convening a wide range of national and sub-national stakeholders that span the categories of research generators (researchers), research users (health providers, purchasers, policymakers), and research beneficiaries (patients). ${ }^{45}$ Including representatives of disadvantaged and marginalised groups is essential because they are likely worst-off in terms of their health, meaning they are the people for whom HSR is aiming to improve the health system as a priority. Decision-making should occur through a deliberative process rather than a top-down or hierarchical one and decisions should reflect the consensus of all the national and sub-national actors involved. ${ }^{46,47}$

'Research for health justice' further demands that the norm of health equity underlie interpretive priority setting processes for health research. One way that this might be actualised is by participants considering 'impact on health equity' when identifying HSR priority topics/questions, including 'impact on health equity' as a ranking criterion for HSR 
topics/questions, and weighting that criterion heavily. Such an approach was recently used in a priority setting exercise facilitated by the Alliance for Health Policy and Systems Research in which policy makers and researchers from four regions identified health systems financing research priorities. The criterion 'impact on health equity' was weighted twice as heavily as other ranking criteria. ${ }^{48}$ In the context of HSR, the framework also requires 'impact on health equity' be interpreted in a particular way. It should be understood to mean how likely research on a particular topic will promote just health system functioning. According the health capability paradigm, a just health system has two main features: 1) equal access to high quality goods and services (i.e. public health goods and services, health care goods and services, and health-related social services ${ }^{49}$ ) and 2) equitable health financing..$^{50}$

Equal access consists of four core elements: horizontal equity, quality, agency, and norms. ${ }^{51}$ This account of equal access is derived from the capability perspective, which draws attention to the fact that the four different elements all affect individuals' freedom to be healthy. To ensure equal access, public health interventions and health care should be distributed in proportion to individuals' health needs. People with similar health needs should receive similar levels of care (horizontal equity) so that they have equal freedom to reduce gaps in their health status from the optimal level. They should not receive unequal levels of care due to differences in their ability to pay, gender, living in a rural area, working in the informal sector, or other such attributes. ${ }^{52}$ Equal access also entails high quality public health interventions, health care, and social services be provided to a state's entire population. ${ }^{53} \mathrm{~A}$ health system in which individuals receive health care of different quality is unjust because two individuals with the same health condition will experience different levels of freedom to achieve health functionings. ${ }^{54}$ The quality of health care accessed by various sub-populations within a country should be the same. Finally, equal access means that societies must promote health norms and the conditions for health agency so that individuals 
are able to make informed judgements and take effective action to convert their health resources into maximum levels of health functioning for themselves. ${ }^{55}$

Aside from equal access, a just health system must offer financial protection for a state's entire population, especially the poor and disadvantaged, against the monetary burdens associated with ill health. Risk pooling provides a measure of financial protection against the vulnerabilities that result from suboptimal health. As such, the health capability paradigm considers universal health insurance to be a requirement of justice. ${ }^{56}$ Significant inequalities in insurance coverage and utilisation across different sub-populations is inconsistent with its requirements. However, simply having universal insurance is not sufficient to ensure individuals' health capabilities. The insurance scheme must also be financed such that the population it covers shares the burden justly, preventing premiums from impoverishing the sick and the poor. Progressive financing mechanisms should be relied upon such as taxation based on ability to pay or social insurance. ${ }^{57}$ Out-of-pocket payments (e.g. co-payments, deductibles, user fees) can create financial disincentives that discourage individuals from using needed health care services and, thereby typically fail to promote their health capabilities. $^{58}$

Beyond its procedural criteria for HSR priority setting, 'research for health justice' demands that the final outputs of the process promote just health system functioning. The priority HSR topics/questions that are identified should include the topics/questions that need to be answered in order to move closer towards equal access and/or universal health insurance that is equitably financed within a particular LMIC health system. These questions should evolve as progress is made towards the two goals.

Selecting a host population and research question (project level) 
Selecting a host population. To promote the reduction of between and within-country inequalities in individuals' health capabilities, the 'research for health justice' framework calls for external research actors not only to perform studies in states that are unable to ensure their populations' health capabilities (i.e. LMICs) but also to focus on worst-off individuals within those countries. How this requirement can be best achieved when selecting a research population with whom to conduct a study is determined by the nature of the research. HSR focuses on improving health systems that service populations rather than developing drugs and vaccines designed for individuals with specific illnesses. Health systems can be conceptualised as operating at three levels: national, sub-national (e.g. states, districts), or sub-district (e.g. communities, municipalities, villages). ${ }^{59}$ Under 'research for health justice', HSR can focus on health systems in LMICs at any of these levels, provided that the population that they service are worst-off in terms of their health. Selecting a host population then entails choosing a national, sub-national, or sub-district entity (or entities) whose population has a large gap in its health status relative to the optimal level. (Here, health status is a proxy indicator for health capability.)

In general, HSR focusing on the national health system of a LMIC will meet the above requirement. To make this determination at the sub-national level, objective indicators may be relied upon such as life expectancy, years of life lost due to disease, and years of life lost due to disability. Selected host populations at the sub-national level should have large gaps in health status relative to other equivalent populations in the country, though not necessarily the absolute largest health gap. For example, if one or more districts are selected to serve as the research population, they should have a large gap in health status relative to the district in the country with the best health. Where there is little variation between districts (i.e. little within-country health inequality), all districts would be acceptable to focus upon under the framework. 
In contrast, international clinical research consists of evaluating new medical interventions by allocating them to individuals drawn from host communities in LMICs. As a result, 'research for health justice' demands that international clinical research be performed with worst-off host communities in LMICs. ${ }^{60}$

Selecting a research question. After determining that a nation, district(s), or community(ies) is worst-off, the next question to consider is how can HSR promote better freedom to achieve health in that host population? Unlike clinical research, HSR cannot advance justice in global health by developing a drug or vaccine to address a disease that is a major contributor to the gap in health status between its host population and the optimal level. Instead, HSR is question-driven and focuses on systems (public health and health care). ${ }^{61}$ HSR asks three main types of research questions:

- what are the hardware and software elements ${ }^{62}$ of a particular health system and what are the relationships and interactions between them?

- do health systems meet their goals and, if not, why not?

- what can be done to improve health systems' functioning to meet their goals? ${ }^{63}$ HSR is often descriptive, explanatory, or exploratory because it can be very unclear what aspects of health systems cause their poor performance and should be targeted by interventions. It can also be evaluative without involving the testing of an intervention (i.e. HSR that evaluates health system performance).

'Research for health justice' requires that HSR questions fall into one (or more) of the following categories: 1 ) investigating where a health system falls short of the requirements of justice, 2) identifying the health system components and other causal factors that contribute to that situation, 3) developing and evaluating strategies to address specific system failings, and/or 4) scaling up those strategies that are proven effective. 'Research for health justice' recognises that HSR that evaluates system performance and the causes of weak system 
functionings is especially vital. Ideally, HSR in these two categories will be linked to subsequent intervention development so that HSR generates improvements in LMIC health systems and, thereby advances justice in global health. An example of such an approach is demonstrated by the Social Health Insurance for Equity in Less Developed countries (SHIELD) project, which focuses on the health systems of Ghana, South Africa, and Tanzania. ${ }^{64}$

Depending on what worst-off population is selected to be the focus of HSR, studies may assess the performance of national, district, or community health systems. To understand how HSR might assess a health system's performance, it is again useful to consider the health capability paradigm's requirements for a just health system. HSR can assist LMICs by evaluating their health systems for elements of equal access and equitable financing. This might entail assessment of:

- progressivity of health system financing mechanism(s) (i.e. whether the system is financed according to people's ability to pay),

- health insurance coverage (breadth and depth) and utilisation across different subpopulations (e.g. by income, gender, rural/urban, etc.),

- financial protection across different sub-populations,

- utilisation of health services across different sub-populations,

- benefit incidence across different sub-populations and types of provider,

- health agency of various sub-populations, and/or

- quality of health care accessed by various sub-populations.

A comprehensive set of indicators for financial protection that are consistent with the health capability paradigm have recently been proposed that might be relied upon for this purpose. ${ }^{65}$ They go beyond narrow indicators of catastrophic spending and impoverishing spending to measure financial protection for health across multiple dimensions to create a "financial protection profile". ${ }^{6}$ 
Where the weaknesses of a health system are known, HSR can explore what the barriers are to achieving the key elements of a just health system. For example, researchers might decide to study the health system in a district where maternal and child health services are utilised more often by affluent individuals. Their research could investigate why poor mothers and children use these services less in the particular district.

HSR can also evaluate and scale up systems-level interventions that promote horizontal equity, high-quality care for all, health agency, and/or universal health insurance. As an example, in 1999, less than one percent of Rwanda's population had health insurance. ${ }^{67}$ To address this problem, a systems-level intervention was introduced called mutuelles, a community-based health insurance program that now covers $85-90 \%$ of the Rwandan population. ${ }^{68}$ Mutuelles was first piloted in 1999 in three districts in Rwanda and evaluated for its impact in those districts. Based on the results, it was then rolled out to the remainder of Rwanda, beginning in $2002 .{ }^{69}$ Since 2007 , the annual mutuelles premium per household is $\$ 1.81$ USD per member, with an exemption for the poorest $16 \%$ of the population. Mutuelles enrolees are entitled to a minimum service package at their designated health centre and at their district hospital. Co-payments exist for both health centre (\$0.36 USD) and hospital ( $10 \%$ of the fee-for-service) visits. ${ }^{70}$

Mutuelles is consistent with 'research for health justice' in that it is an intervention designed to achieve universal health insurance and is progressively financed to the extent that the poorest are exempt from annual premiums. However, mutuelles use of co-payments may be regressive, depending on their impact on poor individuals' health care utilisation and financial protection. (If it is the case, then this element of mutuelles would be inconsistent with 'research for health justice' and require modification.) The HSR performed to evaluate mutuelles between 2000 and 2008 further upheld framework requirements by assessing the intervention's impact on aspects of equal access and equitable financing across sub- 
populations stratified by income,$^{71}$ though this could have been supplemented by data on other sub-populations. ${ }^{72}$

This example also demonstrates that, where HSR identifies weaknesses in a national health system, it can lead to interventions being developed and evaluated in pilot studies conducted with a small proportion of the country's population. Here, it is important that the sub-national or sub-district entities selected for the intervention's initial allocation and evaluation are worst-off.

A second criterion for HSR questions is that the process by which they are selected be inclusive and the chosen research question reflect consensus amongst stakeholders. Since externally-funded HSR in LMICs is a collaboration between external and local researchers, both should be involved in the selection of the research question. The 'research for health justice' framework recognises that, depending on the stage of the research partnership, the actor(s) who takes the lead in the selection process may change. Early on, senior external researchers may be more likely to do so, though local researchers must be included in the selection process and agree with the research question chosen. Over the course of such partnerships, local researchers' HSR capacity should be enhanced. For long-term partnerships (i.e. 10 years or more), 'research for health justice', therefore, requires that senior local researchers take the lead in selecting research questions. Input from health care recipients from the host population, especially those from vulnerable and marginalised groups, should be taken into consideration. ${ }^{73}$ To promote the translation of HSR evidence into policy, the framework also recommends that relevant LMIC health policymakers (e.g. government health officials and/or health facility administrators) be included in the research question selection process.

A third consideration is whether national HSR priorities have been set by the host country in accordance with framework requirements and, if so, whether the research question aligns 
with them. As global actors are obliged to work with states to ensure their populations' health capabilities, it is important that they respect those HSR topics and questions that have been identified as being of highest concern by host countries. At present, many LMICs have not identified national HSR priorities ${ }^{74}$ and, although global priorities such as the Millennium Development Goals (MDGs) do exist, it is not sufficient for HSR questions to align with global priorities in order to meet the requirements of 'research for health justice'. ${ }^{75}$ While it is acceptable for HSR questions to be consistent with global priorities, where national HSR priorities have not been determined by a country, having HSR meet the framework's first and second criteria for selecting a research question is considered more critical by 'research for health justice'.

A fourth criterion is that the research question has not been previously addressed because it is an inefficient use of HSR resources to study questions that have already been answered. A clear need for HSR on the particular topic should exist. Finally, when HSR involves testing an intervention, 'research for health justice' requires that it be appropriate for its context. As an example, if evidence indicates that poor utilisation of health services by women in a LMIC is primarily due to an insufficient number of health workers skilled in reproductive and child health, the response should not be HSR to develop and evaluate an intervention to improve the supply chain for vaccines for childhood illnesses. The intervention that is developed should address the specific barrier(s) to access experienced by the particular worst-off population. Intervention appropriateness can be facilitated by pairing explanatory HSR (category 2) with HSR that evaluates an intervention (category 3), allowing strategies to improve a specific health system to be designed in light of the evidence of the causes of its weaknesses.

\section{Obligation-bearers}


The selection of research targets in HSR occurs at a number of different stages or levels: priority setting at the global and national levels, the design of funding schemes by funding agencies, the selection of research questions by researchers (i.e. project level), and the selection of research projects to finance by funders. Different actors' roles entail that they are involved at different stages of this process. In accordance with the functional requirements principle, the obligations of various actors are summarised in Table 1.

\section{Research capacity strengthening}

Capacity-building at the systems, institutional, and individual levels

States have an obligation to establish health research systems as part of their duty to ensure their populations' health capabilities. ${ }^{76}$ Where states are unable to fulfil this duty, global actors must build their capacity to generate evidence on the effectiveness of health interventions, services, and systems by promoting the development of sustainable national health research systems. ${ }^{77}$ Under 'research for health justice', HSR capacity-building at the systems, institutional, and individual levels is then a required investment.

Framework requirements for the content of HSR capacity-building in LMICs are largely similar to its requirements for clinical research capacity-building ${ }^{78}$ (Box 1). Yet certain differences are present, which will be briefly discussed. At the health research systems level, capacity strengthening should enhance core functions like priority setting, with the objective that host country actors become able to perform them on their own. For HSR, as previously discussed, priority setting should rely on interpretive rather than disease-driven methods. Priority research topics or questions should be selected (in part) on the basis of their impact on health equity (equal access and equitable financing). 
At the project and institutional levels, capacity-building efforts should enhance research institutions and individuals' abilities to conduct HSR that promotes just health systems. Developing capacity to perform HSR that assesses system performance, identifies the causes of poor system performance, and develops interventions to address them, with a particular focus on equal access and equitable financing, is a necessary requirement. Doing so might consist of assisting institutions to develop clear institutional goals for HSR and strategies to achieve those goals, strengthen their ability to generate and allocate financial resources to HSR, create a formal home (e.g. department, centre) for HSR, develop degree curricula for HSR that include study on what health equity is and how HSR can promote it, and/or train a core set of researchers in HSR concepts and methods. Collectively, these researchers should have expertise in number of methods because HSR relies on a diverse range of qualitative, quantitative, and mixed method approaches. ${ }^{79} \mathrm{HSR}$ capacity-building should also focus on improving research institutions and researchers' conduct of researchto-policy activities. Doing so might consist of establishing research-uptake units, emphasising research uptake concepts and skills in HSR curricula, carrying out investigator training on communicating evidence to policymakers, or modifying institutional policies to reward staff for ensuring the translation of systems-level interventions post-study. ${ }^{80}$

Beyond the supply side, it is highly desirable that HSR capacity strengthening address the demand-side (policymakers and policy institutions). To create demand for HSR evidence, capacity-building efforts might seek to promote a culture of evidence-based health policymaking at the national, district, or local government levels, develop in-house units for synthesising and analysing research evidence in policy institutions, or train policymakers in the use of HSR evidence.

Finally, the framework requires that capacity-building partnerships at all three levels be tailored to fit their context. This means that external actors should seek to address the specific weaknesses of the LMIC health research system, institutions, or researchers with 
whom they are partnered. Evidence indicates that, although studies have shown that such tailored approaches are more effective at building HSR capacity, external actors have tended to utilise one-size-fits-all approaches in LMICs. ${ }^{81}$ Doing so constitutes an inefficient use of resources, which is inconsistent with the health capability paradigm.

\section{Obligation-bearers}

The nature of external actors' obligation to carry out research capacity strengthening varies according to the roles they typically perform. Accordingly, governments of high-income countries have an obligation to create strong policy incentives for HSR capacity strengthening in LMICs and to abolish policies that create barriers or disincentives to doing such capacity-building. Major funders of HSR in LMICs (e.g. international and bilateral aid agencies) are often part of the development sector. ${ }^{82}$ Under the health capability paradigm, development aid should support direct assistance for health (i.e. provision of health care, conduct of health research) and capacity-building to ensure the health capabilities of LMIC populations. All development agencies, therefore, have an obligation to fund health research, including HSR, and to support the development of sustainable health research systems in LMICs. This obligation contrasts with the view and practice of many donor governments, as they do not see research as a component of official development assistance. $^{83}$

The capacity-building component of the obligation entails funding capacity strengthening at the systems, institutional, and individual levels for HSR (as well as other forms of health research). Such a requirement draws attention to a number of shortcomings in current practice. At present, bilateral aid agencies that support research capacity strengthening in LMICs do not necessarily fund significant amounts of HSR capacity-building, preferring to channel money to clinical and epidemiological research capacity-building. ${ }^{84}$ Of those agencies that do support HSR capacity strengthening, they often fail to direct resources to 
capacity-building at the systems-level. ${ }^{85}$ For example, the goal of research capacity-building for the United Kingdom's Department of International Development (DFID) is to facilitate individual and organisational learning. ${ }^{86}$

Aside from strengthening health research systems' capacity to set priorities, finance, and regulate HSR, development agencies should also fund research capacity-building as part of HSR projects and long-term research partnerships between institutions. They might even fund partnerships dedicated solely to capacity-building such as the Consortium for Health Policy \& Systems Analysis in Africa. ${ }^{87}$ In all cases, the intention to tailor capacity-building strategies to the context in which they are implemented and to demonstrate that this has been done should be a requirement of funding.

As sponsors of HSR from high-income countries generally work at the institutional level, they are obligated to establish enduring relationships with LMIC institutions that (over time) build these institutions' capacity to conduct HSR on their own. Such partnerships can involve LMIC research institutions and/or policy institutions. Researchers work at the project level and, as a result, are required to build research capacity (mainly at the individual level) as part of their HSR projects and to establish long-term collaborations with health systems researchers and policymakers in LMICs.

\section{Post-study benefits}

Identifying what is owed post-study in HSR

HSR can most feasibly support the development of one element necessary to achieve worstoff individuals' health capabilities: "enabling public health and health care systems". ${ }^{88}$ It can promote just health systems in LMICs most directly by implementing interventions that effectively strengthen performance on dimensions of equal access and equitable financing. 
Yet HSR of this type often relies on the prior conduct of HSR to identify areas of poor system performance (category 1 ) and their underlying causes (category 2). This has implications for the nature of post-study benefits that HSR actors are obligated to provide.

Where HSR evaluates health system performance at the national, sub-national, or subdistrict level (category 1), it produces data that, on its own, cannot be used to improve health system functioning. It is not clear how or why the system falls short of the requirements of justice, what system components are involved, or what changes to policy and practice are required to boost system performance. As such, where HSR finds poor system performance on dimensions of justice, the post-study benefit owed by external research actors to host populations is to continue to work with local researchers and policymakers to design followup studies to investigate its causes.

HSR that explores why particular health system weaknesses occur (category 2) gives rise to evidence that helps identify where changes to policy and practice should be targeted to promote justice. However, such research will not necessarily confirm that such changes are effective. When exploratory and explanatory HSR is performed, the post-study benefit owed by external research actors is to work with local researchers and policymakers to design follow-up studies to design and evaluate systems-level interventions that address identified barriers to just health systems.

HSR that assesses systems-level interventions (category 3) has the potential to directly improve health systems in accordance with the requirements of the health capability paradigm. Where interventions are proven successful, this potential can be realised through their sustained implementation. Accordingly, 'research for health justice' proposes that a duty to implement systems-level interventions proven effective is owed post-study. Poststudy implementation rather than access is owed because systems-level interventions typically consist of new policies and programs/initiatives or modifications to existing ones. 
Examples of systems-level interventions include (but are not limited to) pay for performance programs, conditional cash transfer initiatives, service delivery mechanisms, and insurance schemes. Pay for performance interventions, for example, consist of a policy directive set at the national, district, or organisational level that requires cash awards be paid to health care providers or organisations upon their achievement of certain targets (for coverage, productivity, utilisation, etc.). ${ }^{89}$ They further involve the implementation of a program to put the policy into practice. This requires actors and organisations to take on the roles and responsibilities (financing, management, administration) necessary to execute program components, which would include securing financing for the program ${ }^{90}$, monitoring staff or organisations for achievement of pay for performance targets, and transferring payments to those who are eligible for rewards.

'Research for health justice' calls for policy elements of successful interventions to be adopted beyond the duration of studies by the entities that participated and to continue being implemented through their associated program(s). Systems-level interventions proven effective are primarily owed to the actors or entities that received them during HSR projects because, as HSR is context-specific, the results of a single study may not apply to households or health facilities in other districts or communities. The specific weaknesses that the intervention addresses may not be present beyond the particular district or community health system, making its implementation elsewhere potentially inappropriate. In some instances, this will require a policy to remain in place and be implemented only in certain districts, municipalities, or villages. In others, it may mean an intervention must continue to be implemented nationally (i.e. where an intervention has been rolled out to the whole country). (As discussed in the next section, the obligation to carry out intervention implementation does not fall on researchers. ${ }^{91}$ )

Although a systems-level intervention proven effective is only owed to the population involved in a particular study, 'research for health justice' recognises that the potential for 
scale-up should not be disregarded. A second post-study benefit that is owed in this situation is for scale-up studies to be completed where there is a high likelihood of intervention effectiveness at scale (such as where an intervention is being implemented in certain districts but the health system weaknesses it combats are experienced nation-wide).

\section{Obligation-bearers}

According to the framework, governments of high-income countries should use policy measures to encourage the delivery of post-study benefits in HSR. One way they might do this is by requiring their country's aid agency to allocate a proportion of its health budget to research knowledge translation (with similar amounts of resources allocated to diseasedriven and non-disease-driven research). HSR funders are obligated to support the provision of post-study benefits through their mandates, the nature of their funding initiatives, and their requirements for applicants to these initiatives. Their mandates should describe a commitment to knowledge translation, defined (for HSR) as the translation of knowledge through follow-up studies, intervention implementation post-study, and, where applicable, scale-up.

Funding initiatives should be established to support linking HSR of categories 1, 2, and 3 together; implementing successful interventions post-study; and capacity-building for knowledge translation for LMIC researchers and policymakers. HSR funders should support grants for long-term programs of HSR that span system performance assessments to intervention development. Funding initiatives for post-study intervention implementation might consist of several types of opportunities:

- Fast-track grants for funding systems-level intervention implementation post-study, where previously funded systems-level interventions are proven effective.

- Fast-track grants for funding scale-up studies, where previously funded systems-level interventions are proven effective. 
- Grants for supporting knowledge translation units at research institutions. ${ }^{92}$

The requirements for applicants to research project grants should include consulting or partnering with LMIC policymakers and, where applicable, providing a strategy for developing an intervention implementation plan as the research proceeds. Applicants should be permitted to include budgetary allocations to support the design and execution of an intervention implementation strategy during a project(s) and the salary of a knowledge translation manager to coordinate these activities. Monitoring of funded HSR projects should then assess that an implementation plan is in fact devised and certain elements are carried out during the research. These elements might include stakeholder analyses and networking with key local actors and institutions who could take on certain implementation responsibilities post-study.

It might be suggested that research funders should not be obligated to take on the responsibility of financing post-study implementation of successful systems-level interventions because doing so is not research-related. 'Research for health justice' does not generally require research funders to finance access to new medical technologies after externally-funded clinical trials end in LMICs. ${ }^{93}$ However, the difference in what many (but not all) external research funders owe after HSR again derives from the fact that they are development organisations and, therefore, have a broader function that encompasses but is not limited to research. ${ }^{94}$ Beyond their health research-related obligations, development agencies have a separate obligation to assist LMICs deliver health care and services through their health systems. One way this obligation might be discharged is through ensuring funding for the post-study implementation of systems-level interventions that are proven effective. It should be noted this obligation would also apply to global health organisations and philanthropic foundations that focus on creating better health systems in LMICs. Returning to the mutuelles example from Rwanda, the Global Fund currently finances mutuelles premiums for the very poor, orphans, and people living with HIV/AIDS 
and co-finances premiums for households classified as poor in Rwanda. ${ }^{95}$ This funding was awarded as part of a Global Fund grant for health system strengthening. ${ }^{96}$

External sponsors of HSR in LMICs have an obligation to establish knowledge translation units that train the health systems researchers they employ to communicate with policymakers about their research. These units should provide researchers with support when they are devising and executing their intervention implementation plans. This might entail assistance with engaging LMIC policymakers and performing stakeholder analyses to gain a better understanding of the policy environment in a specific host country. These units should proactively form relationships with policymakers and policy institutions in LMICs, serving as the external sponsor institution's link to such actors. External sponsors from highincome countries also have duty to build LMIC research institutions capacity for HSR knowledge translation through long-term partnerships as part of their capacity-building obligations. They further have an obligation to incentivise the health systems researchers they employ to carry out implementation activities in LMICs. Incorporating the conduct of such activities into performance review or promotion criteria would be one way to uphold that obligation.

External health systems researchers' post-study obligations vary slightly depending on the category of HSR that they are performing in LMICs. Four core obligations apply to all external researchers and an additional obligation is owed by researchers doing interventionfocused HSR. First, external health systems researchers from high-income countries are obligated to conduct formative work to understand the nature of the policy process and who the relevant policymakers and stakeholders are in the context of their host population. For intervention-focused HSR, this includes determining which actors need to be on board in order for post-study implementation to occur, to determine their view of the intervention, and to try to alter any negative opinions held by relevant stakeholders who have high levels of power and influence. Second, health systems researchers should engage or partner with 
policymakers (health officials and/or health facility managers) identified as relevant throughout the research process. Third, health systems researchers have an obligation to develop their own capacity to communicate research findings to LMIC policymakers and to serve as policy entrepreneurs. Finally, health systems researchers have an obligation to conduct follow-up HSR (category 2 or category 3) in order to ensure that HSR is (eventually) performed whose outputs can directly improve health system functioning in LMICs.

Where external health system researchers perform intervention-focused studies, they acquire an additional obligation to develop and execute an intervention implementation strategy. The objective of the strategy is to ensure that policy components of the intervention remain adopted by participating health facilities and/or governments post-study and that their implementation is smoothly handed over to local and/or external actors involved in health programming or health systems strengthening. The 'research for health justice' framework does not consider the same actor (i.e. researchers) to be obligated to conduct the research and to deliver interventions proven successful post-trial. Actors acquire their obligations based on their functions, which is why researchers and research institutions are obligated to perform HSR and health programming agencies and their staff are obligated to implement interventions post-study.

\section{Conclusions}

'Research for health justice' takes the position that HSR should be a major focus of international research investment because HSR is needed to reduce shortfalls in individuals' health capabilities between and within countries. At present, funding for HSR is estimated to comprise only $1.6 \%$ of investment in international research, which is inconsistent with the framework. ${ }^{97}$ 
Beyond articulating a philosophical argument for increased international funding for HSR in LMICs, this paper considers the model of HSR to which this investment should be directed. A specific form of HSR is required in LMICs if the enterprise is to advance justice in global health. At the project level, 'research for health justice' requires externally-funded HSR in LMICs to be targeted to populations at the national, sub-national, or sub-district level who are worst-off in terms of their health. HSR questions should fall into one (or more) of the following categories as a matter of priority:

- investigate where a health system falls short of the requirements of justice (i.e. equal access and equitable financing),

- identify health system components and other causal factors that contribute to an unjust health system, and/or

- develop and evaluate interventions to address such system failings.

In light of the requirements of shared health governance and the policy-driven nature of HSR, research questions should also align with the national priorities of host countries, be determined through an inclusive process that involves local researchers and policymakers, and reflect consensus amongst all parties. Ideally, programs of HSR will be carried out that consist of projects in the former two categories that are then linked to projects that evaluate an intervention(s).

HSR should be carried out in partnership with local research institutions and researchers in LMICs, wherever possible, and should build their capacity to conduct equity-oriented HSR independently. This capacity-building should be tailored to match the specific needs of health research systems, institutions, and/or researchers in host countries. Where HSR develops and evaluates systems level interventions, those interventions proven effective should be implemented post-study in those districts/cities/villages that participated in the project. This is to be financed by a health development funder and carried out by local and/or external actors involved in health programming or health systems strengthening. 
Aside from the project level, the 'research for health justice' framework derives additional guidance for HSR priority setting at the national level and research capacity strengthening at the systems and institutional levels. Here, the framework draws attention to the fact that changes at the project level alone will not suffice to connect HSR in LMICs to increased freedom to achieve good health for the worst-off. Global actors, especially multilaterals and research funders, have ethical obligations beyond funding individual HSR projects to support the conduct of the type of HSR described by 'research for health justice'. It is also important to note that obligations such as these fall outside the typical system of research ethics oversight (i.e. IRB system). In order to promote adherence to broader obligations of priority setting and research capacity-building, a new or expanded form of oversight will likely be necessary.

The paper demonstrates that the unique features of HSR give rise to a number of framework requirements for selecting a research target, research capacity strengthening, and poststudy benefits that differ or are nuanced relative to framework requirements for international clinical research. For example, HSR questions should identify and address specific aspects of health systems that generate unequal access and inequitable financing for LMIC populations, whereas international clinical research ought to focus on specific diseases that are a major contributor to host communities' gap in health status from the optimal level. ${ }^{98}$ Additionally, where HSR funders have a role in development, their obligations are more extensive than those of international clinical research funders.

There are currently no HSR-specific guidelines for international research ethics. Ethical guidance documents that address international research (e.g. the Council for International Organizations of Medical Sciences' guidelines) primarily consider biomedical studies with human subjects. Based on the findings of this paper and others, we advocate for the 
development of HSR-specific guidance to be incorporated into such documents or to be the focus of a separate set of international guidelines. ${ }^{99}$

The 'research for health justice' framework has a number of limitations in its current form and requires further development. First, the framework only describes three aspects of an HSR model that advances justice in global health, rather than providing a more comprehensive description. Second, it identifies the obligations of research actors external to LMICs but does not describe the obligations of research funders, sponsors, and investigators from LMICs. Third, the framework's reliance on the health capability paradigm restricts the scope of its guidance in several ways. The issue of power disparities, which are inherent in the conduct of international research, is only considered indirectly by the framework through its requirements for inclusive priority setting and research capacity-building. This is due to the fact that the health capability paradigm "puts forward a set of principled ideas to shift from material and power interests to moral concerns." ${ }^{100}$ How to proceed in the interim under non-ideal conditions (i.e. power disparities) is less considered by the paradigm. ${ }^{101}$ It does not offer guidance on how to undertake "inclusive decision-making" or reach "consensus" when the stakeholders involved in priority setting have unequal levels of power, as is likely to be the case between external and local researchers. For an equity-oriented ethical framework to be relevant to the current practice of research actors, we feel that it must explicitly consider dimensions of power and how to navigate them to promote health equity.

The health capability paradigm also integrates substantive and procedural elements of justice but does not describe how to address the inherent tension between them. ${ }^{102}$ It is, therefore, difficult to derive guidance on matters such as what research actors should do when procedural requirements for national HSR priority setting are met by a LMIC but fail to generate priorities that relate to improving the health of certain worst-off sub-populations. Finally, the framework does not consider how researchers' obligations of health justice are prioritised relative to their obligations of justice in other spheres (education, environment, 
etc.) or other obligations (i.e. of rescue, entrustment, autonomy, beneficence, etc.) and what trade-offs are permissible.

Ultimately, however, the health capability paradigm does enable the derivation of duties for specific external research actors from high-income countries in relation to three aspects of HSR in LMICs. The work presented in this paper to expand the 'research for health justice' framework takes a first step towards describing the model of HSR that external research funders should invest in and researchers should conduct to promote health equity.

\section{References}

1. S.R. Benatar and P.A. Singer, 'A New Look at International Research Ethics,' British Medical Journal, 321 , no. 7264 (2000): 824-826, at 826 .

2. S.R. Benatar and K. Shapiro, 'HIV Prevention Research and Global Inequality: Steps Towards Improved Standards of Care,' Journal of Medical Ethics, 31, no. 1 (2005): 39-47; E.J. Emanuel, Global Justice and the "Standard of Care" Debates, in J. Millum and E.J. Emanuel, eds., Global Justice and Bioethics (Oxford, United Kingdom: Oxford University Press): 181-212; A.J. London, 'Justice and the Human Development Approach to International Research,' Hastings Center Report, 35, no. 1 (2005): 24-37.

3. These theories take the position that the scope of justice is global. We recognise that, while there are strong arguments for this claim, it is not universally supported. Anti-cosmopolitan theorists like David Miller assert that the scope of justice is national and that parties only have obligations of justice to other parties within their nation-states. See L. Ypi, R.E. Goodin, and C. Barry, 'Associative Duties, Global Justice, and the Colonies,' Philosophy and Public Affairs, 37, no. 2 (2009): 103-135.

4. B. Pratt, D. Zion, and B. Loff, 'Evaluating the Capacity of Theories of Justice to Serve as a Justice Framework for International Clinical Research,' American Journal of Bioethics, 12, no. 11 (2012): 30-41.

5. B. Pratt and B. Loff. 'A Framework to Link International Clinical Research to the Promotion of Justice in Global Health,' Bioethics, (2012), doi: 10.1111/bioe.12009.

6. J.P. Ruger, Health and Social Justice (Oxford, United Kingdom: Oxford University Press): at 94-95.

7. J.P. Ruger, 'Health Capability: Conceptualization and Operationalization,' American Journal of Public Health, 100, no. 1 (2010): 41-49.

8. See Ruger, supra note 6 : at 81-83; 88-95.

9. J.P. Ruger, 'Global Health Justice,' Public Health Ethics, 2 (2009): 261-75, at 269. 
10. In this paper, subsequent references to the worst-off refer to those who are worst-off in terms of their health.

11. Global actors are public or private entities from outside a particular state and include multilaterals, bilaterals, global health institutions, governments, nongovernmental organisations, businesses, foundations, families, and individuals. See Ruger, supra note 9.

12. J.P. Ruger, 'Normative Foundations of Global Health Law,' Georgetown Law Journal, 96, no. 2 (2008): 423-443.

13. See Ruger, supra note 9.

14. See Pratt, supra note 5.

15. Although others have used the terms funder and sponsor interchangeably, we distinguish between the two in this article because, in international research, they are often not the same entity. The sponsoring institution is typically the employer of study investigators rather than the agency from whom funding is awarded. In the Mutuelles trial that we discuss later on, for example, the funder was the Doris Duke Charitable Foundation and the external sponsor was Harvard University.

16. See Pratt, supra note 5.

17. See Ruger, supra note 9.

18. See Pratt, supra note 5.

19. See Ruger, supra note 7.

20. WHO Task Force on Health Systems Research, The Millennium Development Goals will not be Attained without New Research Addressing Health System Constraints to Delivering Effective Interventions (Geneva, Switzerland: WHO, 2005).

21. I. Rudan, S. El Arifeen, and R.E. Black et al., 'Childhood Pneumonia and Diarrhoea: Setting our Priorities Right,' Lancet Infectious Diseases, 7, no. 1 (2007): 56-61.

22. This is consistent with sentiments expressed by the World Health Organization and at global ministerial summits on health research. See WHO Task Force on Health Systems Research, supra note 20; WHO Task Force on Research Priorities for Equity in Health and the WHO Equity Team, 'Priorities for Research to Take Forward the Health Equity Policy Agenda,' Bulletin of the World Health Organization, 83 (2005): 948-95; Bamako Call to Action on Research for Health, November 17-19, 2008, THE GLOBAL MINISTERIAL FORUM ON RESEARCH FOR HEALTH, Bamako, Mali; The Mexico Statement on Health Research, November 16-20, 2004, THE MINISTERIAL SUMMIT ON HEALTH RESEARCH, Mexico City, Mexico.

23. See Pratt, supra note 5.

24. See Emanuel, supra note 2.; see London, supra note 2. 
25. S. Bennett, T. Adam, and C. Zarowsky et al., 'From Mexico to Mali: Progress in Health Policy and Systems Research,' Lancet, 372, no. 9649 (2008): 1571-1578; A.A. Hyder, A. Rattani, and C. Krubiner et al., 'Ethical Review of Health Systems Research in Low and Middle Income Countries: A Conceptual Exploration,' American Journal of Bioethics, 14, no. 2 (2014): 28-37.

26. World Health Organization, Scaling up Research and Learning for Health Systems: Now is the Time (Geneva, Switzerland: World Health Organization, 2009).

27. L. Gilson, Health Policy and Systems Research: A Methodology Reader (Geneva, Switzerland: Alliance for Health Policy and Systems Research, 2012).

28. Some public health research can be considered HSR. Hoffman $(2012,13)$ states that "[t]he overlap [of HSR] with population health research, however, is less clear, but likely includes research on the public health system and the delivery of non-personal public health programs and interventions. Excluded from health systems research would be population health research's focus on measuring or describing health, examining the determinants of health status and outcomes, and assessing the effects of specific health promotion interventions.” See S. Hoffman, J-A. Røttingen, and S. Bennett et al., 'Background Paper on Conceptual Issues Related to Health Systems Research to Inform a WHO Global Strategy on Health Systems Research,' 2012, at <http://www.who.int/alliancehpsr/alliancehpsr_backgroundpaperhsrstrat1.pdf> (last accessed Jan. 20, 2014).

29. Here, we acknowledge that it is possible to develop guidance on externally-funded HSR in LMICs from a global justice perspective using other theories of justice. However, as per the health capability paradigm, these theories would need to discuss just health systems and the requirements of global justice in-depth in order to facilitate the derivation of requirements for equity-oriented HSR. For example, Daniels' extension of Rawlsian justice does the former but does not do the latter in sufficient detail. See Pratt, supra note 4.

30. This is not to suggest that obligations of justice are not allocated to LMIC research actors. However, identifying the obligations of research actors in LMICs is beyond the scope of this paper. The nature of these obligations should be explored in future work to determine if host country research actors' obligations mirror, overlap, or are distinct from those of external research actors from high-income countries.

31. See Ruger, supra note 6: at 8-11; Ruger, supra note 9.

32. Alliance for Health Policy and Systems Research (AHPSR), Priority Setting for Health Policy and Systems Research (Geneva, Switzerland: WHO, 2009); Council on Health Research for Development (COHRED) and Swedish International Development Cooperation Agency (SIDA), Cameroon: Alignment and Harmonization in Health Research (Geneva, Switzerland: Council on Health Research for Development, 2008); Council on Health Research for Development (COHRED) and Swedish 
International Development Cooperation Agency (SIDA), Mozambique: Alignment and Harmonization in Health Research (Geneva, Switzerland: Council on Health Research for Development, 2008).

33. This was largely due to countries using disease-driven priority setting methods that devalue HSR and then failing to identify HSR priorities through a separate process. See Council on Health Research for Development (COHRED) and Swedish International Development Cooperation Agency (SIDA), Zambia: Alignment and Harmonization in Health Research (Geneva, Switzerland: Council on Health Research for Development, 2008); Council on Health Research for Development (COHRED), 'Essential National Health Research in South Africa: Towards National Consensus Building in Health Research,' 2001, at <http://www.cohred.org/downloads/669.pdf> (last accessed Jan. 20, 2014).

34. National Institute for Medical Research (NIMR), Tanzania Health Research Priorities, 2006-2010 (Dar es Salaam, Tanzania: National Institute for Medical Research, 2006).

35. This obligation will be discussed in the capacity-building section.

36. M.K. Ranson and S. Bennett, 'Priority Setting and Health Policy and Systems Research,' Health Research Policy and Systems, 7 (2009): 27.

37. Ad Hoc Committee on Health Research Relating to Future Intervention Options, Investing in Health Research and Development (Geneva: World Health Organization, 1996).

38. See Ranson, supra note 36.

39. The malERA Consultative Group on Health Systems and Operational Research, 'A Research Agenda for Malaria Eradication: Health Systems and Operational Research,' PLoS Medicine, 8, no. 8 (2011): e1000397.

40. See Ruger, supra note 6: at 95-98.

41. See Ranson, supra note 36.

42. A. Mills, 'Health Care Systems in Low- and Middle-Income Countries,' N. Engl. J. Med., 370 (2014): $552-$ 557.

43. S. Bennett, I.A. Agyepong, and K. Sheikh et al., 'Building the Field of Health Policy and Systems Research: An Agenda for Action,' PLoS Medicine, 8, no. 8 (2011): e1001081.

44. J.P. Ruger, 'Shared Health Governance,' American Journal of Bioethics, 11, no. 7 (2011): 32-45, at 33.

45. C. Wachira and J.P. Ruger, 'National Poverty Reduction Strategies and HIVIAIDS Governance in Malawi: A Preliminary Study of Shared Health Governance,' Social Science and Medicine, 72, no. 12 (2011): 1956-1964.

46. Id. See Ruger, supra note 6: at 6-8; Ruger, supra note 44.

47. Here, we recognise that further work is needed to further define and operationalize the concepts of "inclusive decision-making" and "consensus". We are currently in the process of carrying it out. 
48. K. Ranson, T.J. Law, and S. Bennett, 'Establishing Health Systems Financing Research Priorities in Developing Countries Using a Participatory Methodology,' Social Science and Medicine, 70, no. 12 (2010): 1933-1942.

49. The exact package of health care that is owed to the population of a particular state is to be determined through a deliberative process at the national level. See Ruger, supra note 6: at 172-202.

50. See Ruger, supra note 6: at 8-11.

51. See Ruger, supra note 6: at 133-157.

52. Id.

53. Id.

54. The principle of equal access to high quality health care does not differ by the voluntary or involuntary nature of risk. Thus, smokers who continue to smoke against health advice are still owed equal access to health goods and services. Since it is extremely difficult to identify how much of choice is voluntary as opposed to due to genetic factors or social conditions, the health capability paradigm errs on the side of social responsibility. It also emphasises developing people's health agency so that they become able to make good health decisions. See Ruger, supra note 6: at 153-155.

55. See Ruger, supra note 6: at 159-171.

56. Id.

57. Id.

58. Id.

59. K. Sheikh, L. Gilson, and I.A. Agyepong et al., 'Building the Field of Health Policy and Systems Research: Framing the Questions,' PLoS Medicine, 8, no. 8 (2011): e1001073.

60. See Pratt, supra note 5.

61. Id; A. Mills, 'Health Policy and Systems Research: Defining the Terrain; Identifying the Methods,' Health Policy and Planning, (2011), doi: 10.1093/heapol/czr006.

62. Health care systems are composed of both hardware (human resources, health services, financing, governance, information technology) and software (norms, values) elements. See Sheikh, supra note 59.

63. See Gilson, supra note 27.

64. D. McIntyre and A. Mills, 'Research to Support Universal Coverage Reforms in Africa: The SHIELD Project,' Health Policy and Planning, 27, suppl 1 (2012): i1-i3.

65. K.T. Nguyen, O.T. Khuat, and S. Ma et al., 'Impact of Health Insurance on Health Care Treatment and Cost in Vietnam: A Health Capability Approach to Financial Protection,' American Journal of Public Health, 102, no. 8 (2012): 1450-1461; J.P. Ruger, 'An Alternative Framework for Analyzing Financial Protection in Health,' PLoS Medicine, 9, no. 8 (2012): e1001294. 
66. See Ruger, supra note 65.

67. Rockefeller Foundation, 'Catalyzing Change: The System Reform Costs of Universal Health Coverage,' 2010, at <http://www.rockefellerfoundation.org/uploads/files/ebafb89b-2d68-45c0-885e74d40e8c55d9.pdf> (last accessed Jan. 20, 2014).

68. Id.

69. By 2005, mutuelles infrastructure covered the entire country. Its impact between 2000 and 2008 was then assessed by a team comprised of researchers from Rwanda and the US (Harvard University). See Rockefeller Foundation, supra note 67.

70. C. Lu, B. Chin, and J.L. Lewandowski et al., 'Towards Universal Health Coverage: An Evaluation of Rwanda Mutuelles in its First Eight Years,' PLoS One, 7, no. 6 (2012): e39282.

71. Id.

72. The precise indicators of financial protection proposed by Jennifer Ruger were not relied upon. They had not yet been devised/published.

73. A.A. Hyder, G. Bloom, and M. Leach et al., 'Exploring Health Systems Research and its Influence on Policy Processes in Low Income Countries,' BMC Public Health, 7 (2007): 309.

74. See AHPSR, supra note 32.

75. Global priorities do not necessarily reflect the specific national contexts, as some global priorities may not apply to certain countries (e.g. countries who have already met certain MDG health targets) and other health problems at the national level may not be included on the list of global priorities.

76. See Pratt, supra note 4.

77. See Pratt, supra note 5.

78. These requirements are discussed in Pratt and Loff (2012). See Pratt, supra note 5.

79. See Gilson, supra note 27.

80. A.A. Hyder, A. Corluka, and P.J. Winch et al., 'National Policy-makers Speak Out: Are Researchers Giving Them What They Need?' Health Policy and Planning, 26, no. 1 (2011): 73-82.

81. S. Bennett, L. Paina, and C. Kim et al., 'What Must be Done to Enhance Capacity for Health Systems Research?' 2010, at <http://www.rockefellerfoundation.org/uploads/files/c4ccb675-f6f8-47de-8552e032d4c3fc20.pdf> (last accessed Nov. 6, 2013).

82. See Bennett, supra note 25.

83. P.R. Hotez, C. Cohen, and T. Mimura et al., Strengthening Mechanisms to Prioritize, Coordinate, Finance, and Execute R\&D to Meet Health Needs in Developing Countries (Washington DC: Institute of Medicine, 2013). This is not to say all development agencies view research and research capacity strengthening as falling outside their remit. A 2001 Overseas Development Institute report that mapped research capacity strengthening initiatives in LMICs identified funding streams available at the following 
agencies: the Danish International Development Agency (DANIDA), the Swedish International Development Cooperation Agency (SIDA)'s Department for Research Cooperation (SAREC), and Canada's International Development Research Centre (IDRC). The United Kingdom's Department for International Development also views research capacity strengthening as being part of its remit and funds both HSR and clinical research in LMICs. See J. Young and N. Kannemeyer. Building Capacity in Southern Research: A Study to Map Existing Initiatives (London, United Kingdom: Overseas Development Institute, 2001); Department for International Development (DFID), 'Capacity Building in Research,' 2010, at <http://bsuhh.org/fileadmin/user_upload/bsuge/Other_Reports/How_To_Note_Research_Capacity_Building.pdf> (last accessed Sept. 14, 2013); Department for International Development (DFID), DFID Research Strategy 2008-2013 Working Paper Series: Capacity Building (London, United Kingdom: Department for International Development, 2008).

84. See Bennett, supra note 25.

85. See Bennett, supra note 81.

86. See DFID, supra note 83.

87. Research funders that do not have a role in development and solely channel their resources to research also have an obligation to fund HSR capacity strengthening that occurs during research-related activities (i.e. institutional collaborations and research projects). They do not have an obligation to fund systems level strengthening.

88. See Ruger, supra note 7 , at 44 .

89. P. Basinga, P.J. Gertler, and A. Binagwaho et al., 'Effect on Maternal and Child Health Services in Rwanda of Payment to Primary Health-care Providers for Performance: an Impact Evaluation,' Lancet, 377, no. 9775 (2011): 1421-1428.

90. During the research project, this responsibility is generally met by the research funder.

91. Here, the framework calls for the handover of intervention implementation to local actors or international NGOs (working with local actors) that are involved in health programming and/or health system strengthening. Their delivery of interventions is supported by funding from aid agency, global health organisation, and/or philanthropic foundation donors (see Obligation-bearers sub-section).

92. These units would focus on getting successful systems-level interventions implemented, unlike technology transfer offices, which focus solely on the commercialisation of new medical technologies.

93. See Pratt, supra note 5.

94. HSR funders that only have a role in research have a narrower obligation to support the provision of post-study benefits. They should support grants for long-term programs of HSR that span system performance assessments to intervention development. Where applicants to funding schemes for HSR 
propose to evaluate an intervention, they should be required to design and execute an intervention implementation strategy during projects and be permitted to request budget allocations to support this.

95. K. Schmidt, 'The Missing Link: The Global Fund and Financial Access to Health Care,' 2010, at <http://www.rockefellerfoundation.org/uploads/files/6485982c-b708-4cc5-af99-ef411035a0f4-gfatmsupport.pdf> (last accessed Sept. 12, 2013).

96. Id. Here, we are not suggesting that bilateral aid agencies, global health organisations, or philanthropic foundations take on the precise Global Fund model of funding for health system strengthening (HSS). It has proven quite difficult for LMICs to be awarded Global Fund HSS grants to support financial access to health services and few have been awarded (See Schmidt, supra note 94). The aforementioned global actors should also not restrict HSS grants on the basis of disease-focus or even require a disease-focus, as many systems-level interventions will be cross-cutting.

97. B. Pratt and B. Loff, 'Health Research Systems: Promoting Health Equity or Economic Competitiveness?' Bulletin of the World Health Organization, 90 (2012): 55-62.

98. See Pratt, supra note 5.

99. See Hyder, supra note 25.

100.J.P. Ruger, 'Author Response to Letter to the Editor: Making Power Visible in Global Health Governance,' American Journal of Bioethics, 12, no. 7 (2012): 65.

101.A.G. Mitra, 'A Social Connection Model for International Clinical Research,' American Journal of Bioethics, 13, no. 3 (2013): W1-W3.

102.Y. Saghai, 'Internalized Public Moral Norms and Shared Sovereignty,' American Journal of Bioethics, 11, no. 7 (2011): 49-51. 
Table 1: Summary of obligations for selecting research targets for HSR in LMICs under the 'research for health justice' framework

\begin{tabular}{|c|c|}
\hline Obligation-bearer & Obligation \\
\hline $\begin{array}{l}\text { International organisations (Alliance for } \\
\text { Health Policy and Systems Research, World } \\
\text { Health Organization, Council on Health } \\
\text { Research for Development) }\end{array}$ & $\begin{array}{l}\text { Facilitate national priority setting } \\
\text { processes for HSR in LMICs in } \\
\text { accordance with framework } \\
\text { requirements (i.e. involve local } \\
\text { stakeholders, be inclusive, generate } \\
\text { consensus, use health equity } \\
\text { criterion) } \\
\text { Refrain from substantially influencing } \\
\text { national HSR priority setting } \\
\text { processes in LMICs }\end{array}$ \\
\hline External governments & $\begin{array}{l}\text { - Create strong policy incentives for the } \\
\text { conduct of HSR that investigates } \\
\text { systems performance, identifies } \\
\text { barriers to equal access and } \\
\text { equitable financing, and develops } \\
\text { interventions to address such } \\
\text { systems weaknesses (e.g. allocating } \\
\text { more money to development } \\
\text { agencies to perform HSR in LMICs, } \\
\text { incentivising research funders to } \\
\text { finance HSR in LMICs) } \\
\text { Abolish policies that create barriers or } \\
\text { disincentives to performing this type } \\
\text { of HSR }\end{array}$ \\
\hline External Funders & $\begin{array}{l}\text { - Set up funding schemes for HSR } \\
\text { programs that investigate systems } \\
\text { performance, identify barriers to } \\
\text { equal access and equitable financing, } \\
\text { and develop interventions to address } \\
\text { such systems weaknesses } \\
\text { - Select projects to fund that are } \\
\text { consistent with framework criteria for } \\
\text { host populations and research } \\
\text { questions (e.g. national not global } \\
\text { priorities) } \\
\text { Refrain from substantially influencing } \\
\text { LMIC national HSR priority setting } \\
\text { processes }\end{array}$ \\
\hline External Sponsors & $\begin{array}{l}\text { - Support researchers to design HSR } \\
\text { projects that evaluate just system } \\
\text { performance, identify barriers to } \\
\text { equal access and equitable financing, } \\
\text { and develop interventions to address } \\
\text { such systems weaknesses. }\end{array}$ \\
\hline External researchers & $\begin{array}{l}\text { Design HSR projects that meet } \\
\text { framework criteria for host } \\
\text { populations and research questions } \\
\text { in collaboration with local researchers } \\
\text { and policymakers. } \\
\text { As part of long-term } \\
\text { collaborations, LMIC }\end{array}$ \\
\hline
\end{tabular}




\begin{tabular}{|l|l|}
\hline & $\begin{array}{l}\text { researchers should take the } \\
\text { lead in the selection of } \\
\text { projects' research questions. }\end{array}$ \\
\hline
\end{tabular}

HSR=health systems research; LMIC=low or middle-income country

Note: This table does not include actors' responsibilities in relation to setting HSR priorities at the global level.

\section{Box 1: Necessary and desirable features of HSR capacity strengthening under the} 'research for health justice' framework

At the health research system level, research capacity strengthening should:

- Build the capacity to identify and coordinate responses to address HSR priorities.

Priority setting for HSR should rely on a mechanism that is interpretive, inclusive, and equity-focused. (Necessary)

- Build the human and physical capacity to conduct HSR on priority research topics and questions. Develop financing mechanisms for HSR. (Necessary)

- Build the capacity of countries with weak national health research systems. If countries are small, this effort may be focused towards sub-regional or regional development. (Necessary)

- Be conducted through partnerships between multilateral agencies and relevant LMIC government agencies that are known to be legitimate and serving the populations' interests. (Necessary)

- Be tailored to address the particular weaknesses of a country's health research system. (Necessary)

- Utilise strategies that have been proven to be effective. (Highly desirable)

- Generally be of lengthy duration. Avoid short-term, ad-hoc relationships. (Highly desirable)

At the institutional and project levels, research capacity strengthening should:

- Involve the transfer of skills, knowledge, and resources that build the independent capacity of LMIC institutions and researchers to perform HSR. (Necessary)

- Relate to assessing system performance, identifying the causes of poor system performance, and developing strategies to address them, with a particular focus on equal access and equitable financing. (Necessary)

- Be conducted through partnerships with LMIC research groups and institutions. (Necessary)

- Build research-to-policy capacity. (Necessary)

- Be tailored to address the particular weaknesses of research institutions and their investigators. (Necessary)

- Utilise strategies that have been proven to be effective. (Highly desirable)

- Address both the supply-side (researchers and research institutions) and the demand-side (policymakers and policy institutions). (Highly desirable)

- Generally be of lengthy duration and span more than one project. (Highly desirable)

- Be consistent with host governments' health research strategies and policies. (Highly desirable)

Note: Bold text indicates that the criterion is unique for HSR capacity-building. Italicised text indicates that the same criterion exists for clinical research capacity-building but has been modified for HSR capacity-building. Underlined text indicates the criterion was identified in relation to HSR but may apply to international clinical research too. All other criteria are the same for capacity-building for clinical research and HSR. 


\section{University Library}

\section{- M M N E R VA A gateway to Melbourne's research publications}

Minerva Access is the Institutional Repository of The University of Melbourne

Author/s:

Pratt, B;Hyder, AA

Title:

Global Justice and Health Systems Research in Low- and Middle-Income Countries

Date:

2015-03-01

Citation:

Pratt, B. \& Hyder, A. A. (2015). Global Justice and Health Systems Research in Low- and Middle-Income Countries. JOURNAL OF LAW MEDICINE \& ETHICS, 43 (1), pp.143-161. https://doi.org/10.1111/jlme.12202.

Persistent Link:

http://hdl.handle.net/11343/56566 